\title{
SEM-EDS-based analysis of the amorphous carbon-treated grinding wheel active surface after reciprocal internal cylindrical grinding of Titanium Grade $2^{\circledR}$ alloy
}

\author{
Krzysztof Nadolny ${ }^{1} \cdot$ Krzysztof Rokosz $^{2}$ - Wojciech Kapłonek ${ }^{3}$ - Marion Wienecke ${ }^{4}$. \\ Jan Heeg ${ }^{4}$
}

Received: 2 August 2016/Accepted: 29 September 2016/Published online: 13 October 2016

(C) The Author(s) 2016. This article is published with open access at Springerlink.com

\begin{abstract}
In this article, we described a detailed analysis of the composition of elements remaining on the amorphous carbon-treated grinding wheel active surface (GWAS) after reciprocal internal cylindrical grinding of Titanium Grade $2^{\circledR}$ alloy. For this purpose, the scanning electron microscope (SEM) combined with energydispersive X-ray spectroscope (EDS) techniques were used. The SEM imaging and observation of selected fragments of active surface of $1-35 \times 10 \times 10-\mathrm{SG} /$
\end{abstract}

Krzysztof Nadolny

krzysztof.nadolny@tu.koszalin.pl

Krzysztof Rokosz

krzysztof.rokosz@tu.koszalin.pl

Wojciech Kapłonek

wojciech.kaplonek@tu.koszalin.pl

Marion Wienecke

marion.wienecke@hs-wismar.de

Jan Heeg

jan.heeg@hs-wismar.de

1 Department of Production Engineering, Faculty of Mechanical Engineering, Koszalin University of Technology, Raclawicka 15-17, 75-620 Koszalin, Poland

2 Division of Surface Electrochemistry and Technology, Faculty of Mechanical Engineering, Koszalin University of Technology, Raclawicka 15-17, 75-620 Koszalin, Poland

3 Subject Group of Metrology and Quality, Department of Production Engineering, Faculty of Mechanical Engineering, Koszalin University of Technology, Racławicka 15-17,

75-620 Koszalin, Poland

4 Institute of Surface and Thin Film Technology, University of Applied Sciences Technology, Business and Design, Wismar, Germany
F46G10VTO grinding wheel was mainly carried out by use of two advanced microscopy systems: JSM5500LV (JEOL Ltd., Tokyo, Japan) and Auriga ${ }^{\circledR}$ (Carl Zeiss Microscopy GmbH, Jena, Germany). During EDS measurements, the Octane plus (EDAX, Inc., Mahwah, NJ, USA) - a high-accuracy silicon drift detector (SSI) was used. Conducted SEM-EDS analysis shows that applied impregnation method ensure the presence of impregnate in a grinding wheel body, also in subsequent work cycles of tool. Observed Ti cloggings on the GWAS appear solely on dulled vertices of active abrasive grains, which demonstrates the limited impact of the impregnate in the zone of direct contact between abrasive grains and machined workpiece surface. However, lack of extensive cloggings of the intergranular spaces indicating an effective removal of long ductile chips of Ti from grinding zone aided by the introduction of an amorphous carbon.

Keywords SEM $\cdot$ EDS · Grinding process $\cdot$ Impregnated grinding wheel $\cdot$ Hard-to-cut materials $\cdot$ Titanium grade $2^{\circledR}$ alloy $\cdot$ Amorphous carbon

$\begin{array}{ll}\text { Nomenclature } \\ \text { AOI } & \text { Area of interest } \\ \text { BEI } & \text { Backscattered electron detector } \\ \text { EDS } & \text { Energy-dispersive X-ray spectroscopy } \\ \text { FIB } & \text { Focused ion beam } \\ \text { GWAS } & \text { Grinding wheel active surface } \\ \text { HVM } & \text { High vacuum mode } \\ \text { LVM } & \text { Low vacuum mode } \\ \text { SDD } & \text { Silicon drift detector } \\ \text { SEI } & \text { Secondary electron image } \\ \text { SEM } & \text { Scanning electron microscopy }\end{array}$

Nomenclature

BEI Backscattered electron detector

EDS Energy-dispersive X-ray spectroscopy

FIB Focused ion beam

GWAS Grinding wheel active surface

HVM High vacuum mode

LVM Low vacuum mode

SDD Silicon drift detector

SEM Scanning electron microscopy 
SESI Secondary electron secondary ion

$a_{a} \quad$ Axial engagement, $\mathrm{mm}$

$a_{d} \quad$ Dressing allowance, $\mathrm{mm}$

$a_{e} \quad$ Working engagement (machining allowance), $\mathrm{mm}$

$a_{e}$ tot Total working engagement (machining allowance), $\mathrm{mm}$

$a_{f} \quad$ Feed engagement, $\mathrm{mm}$

$b_{s} \quad$ Width of the grinding wheel measured parallel to

the wheel axis, mm

$b_{w} \quad$ Workpiece width, mm

$d_{s} \quad$ Grinding wheel outer diameter, $\mathrm{mm}$

$d_{w} \quad$ Workpiece diameter, mm

$h_{s} \quad$ Grinding wheel inner diameter, $\mathrm{mm}$

$i_{d} \quad$ Number of dressing passes

$n_{s} \quad$ Grinding wheel rotational speed, $\min ^{-1}$

$n_{s d} \quad$ Grinding wheel rotational speed while dressing, $\min ^{-1}$

$n_{w} \quad$ Workpiece rotational speed, $\min ^{-1}$

$Q_{d} \quad$ Diamond dresser mass, kt

$Q_{G F} \quad$ Grinding fluid flow rate, $\mathrm{L} \mathrm{min}^{-1}$

$t_{g} \quad$ Grinding time, $\mathrm{s}$

Ua SEM microscope accelerating voltage, $\mathrm{V}$

$v_{f a} \quad$ Axial table feed speed while grinding, $\mathrm{mm} \mathrm{s}^{-1}$

$v_{f d} \quad$ Axial table feed speed while dressing, $\mathrm{mm} \mathrm{s}^{-1}$

$v_{f r} \quad$ Radial table feed speed while grinding, $\mathrm{mm} \mathrm{min}^{-1}$

$\mathrm{v}_{\mathrm{s}} \quad$ Grinding wheel peripheral speed, $\mathrm{m} \mathrm{s}^{-1}$

$v_{w} \quad$ Workpiece peripheral speed, $\mathrm{m} \mathrm{s}^{-1}$

$V_{b} \quad$ Volume of bond in the grinding wheel, \%

$V_{g} \quad$ Volume of abrasive grains in the grinding wheel, $\%$

$V_{p} \quad$ Volume of pores in the grinding wheel, $\%$

\section{Introduction}

Titanium (Ti) is an element of atomic number 22. It occurs in two allotropic forms: $\operatorname{Ti} \alpha$ and $\operatorname{Ti} \beta$. Variation $\alpha$ is crystallized at room temperature in a hexagonal configuration and at a temperature of $882.5^{\circ} \mathrm{C}$ is converted to a high temperature $\mathrm{Ti} \beta$ crystallizing in the regular system. Ti is characterized by a very low thermal conductivity of $11.4 \mathrm{~W} \mathrm{~m}^{-1} \mathrm{~K}^{-1}$, which is 3-4 times smaller than for iron and up to 16 times lower than for copper. In soft state, Ti has a tensile strength $R_{m}=460$ $590 \mathrm{MPa}$. Titanium has a high ductility and excellent corrosion resistance to sea water, chlorides, organic acids, and air atmosphere; no oxidation at $200{ }^{\circ} \mathrm{C}$ and has a high creep resistance at high temperature. Pure, unalloyed titanium is used mainly in the construction, which is required to have high corrosion resistance. These include chemical equipment and rigs working in the surrounding seawater as well as elements used in medical technology and watch making, what described Leyens and Peters in the work [1].

Large industrial importance is given in particular titanium alloys. It results from twofold lower density as compared with iron alloys and high strength of up to $1400 \mathrm{MPa}$. This provides the significant advantage with respect to iron alloys because of the strength-to-weight ratio. Titanium alloys have also a lower modulus of elasticity than steel or nickel-based superalloys which translates into approx. twice as much elasticity. Leyens and Peters in the work [1] listed the most important industries which use titanium alloys. These include, among others:

- Chemical industry (reactors, tanks, heat exchangers, apparatus precise);

- Petrochemical industry (installations and equipment in the refineries);

- Power industry (condensers, steam condensers, heat exchangers, steam turbines in power plants, and power plants);

- Shipbuilding industry (seawater pump, valves, hulls of submarines, and bathyscaphes);

- Automotive industry (exhaust systems, suspension components, drive shafts, springs, control arms);

- Aerospace industry (coverage hull, chassis, parts of rockets and shuttles, construction of wings, and helicopter rotors);

- Medical industry (implants, bone fasteners, surgical instruments, test equipment, wheelchairs);

- Sports equipment industry (bicycle frames, steering wheels, golf clubs and hockey, mountaineering equipment, tennis rackets, accessories, and other sailboats).

Titanium and its alloys, characterized and described in numerous works [5-9], belong to so-called hard-to-cut materials. This is mainly due to:

- Low coefficient of thermal conductivity, thereby the heat generated in the cutting zone is not dissipated and focused on the edges and vertices of the cutting blade;

- High temperature (in the cutting zone exceeding even $1100{ }^{\circ} \mathrm{C}$ ) leads to the heavy wear of blade and its plastic deformation;

- High temperature in the cutting zone, causing also the strengthening phenomenon and growth of cutting resistance;

- The strong chemical affinity of titanium for tool materials, which promotes adhesion of chips to the cutting tools and, consequently, their rapid blunting and chipping;

- High elasticity of titanium, resulting in deflection and vibrations during machining, which affects on momentary changes in the depth of cut. At small depths of cutting, cutting by blade no longer takes place, only plastic deformation, which results in strengthening of the workpiece material and increasing of its strength and hardness. 
The main factors affecting the grindability of titanium and its alloys, detailed studies, and discussions in a number of works [2-9], include, among others:

- High ductility;

- High values of coefficients of friction;

- Susceptibility to strengthen during grinding due to high temperatures;

- The chemical reactions between the surface of the object and the abrasive grain.

As a result of titanium alloys, high ductility during grinding ductile chips are formed with large size and irregular shapes. These types of chips, forming in high temperatures (above $1000{ }^{\circ} \mathrm{C}$ ) have a high propensity to clogging of the abrasive tools active surface. This phenomenon is further enhanced by the high intensity of abrasive wear of the abrasive grains vertices, which is a result of their thermal and thermo-fatigue wear. To counteract this phenomenon, the grinding process is carried out at lower speeds of wheel, with values from one third to half the speed used in conventional grinding. Lowering the grinding speed also favors the formation of residual stresses with smaller values in the workpiece surface, but in turn, causes a rapid blunting of abrasive grains, especially when grinding wheels with $\mathrm{Al}_{2} \mathrm{O}_{3}$ abrasive grains are used, as what was described in the works [2-9].

Another way of counteracting the phenomenon of clogging of the grinding wheel active surface (GWAS) by ductile chips of titanium is the application of abrasive tools with modifications of its construction. The most common are the use of multiporous and impregnated grinding wheels, widely described in the works [10-13].

Multiporous wheels have increased volume of intergranular free spaces between abrasive grains, which make it easy to transport chips from the grinding zone, as well as the introduction of grinding fluid into the contact zone between the wheel and the machined surface. The second of abovementioned modifications (impregnation of abrasive tools) consist of introduction of anti-adhesive and lubrication agents which actively influence the conditions in the grinding zone, as what was discussed by Webster and Tricard [14] as well as Chirkov [15]. Impregnation of the grinding wheels is one of the easiest ways to modify standard tools and effectively influence the chemical conditions in the zone of contact between active vertexes of abrasive grains and the workpiece surface in order to counteract the phenomenon of clogging. In literature, descriptions of the use of various impregnating substances (sulfur, paraffin, wax, graphite, molybdenum disulfide, silicone) introduced by gravity or pressure methods into the wheel body can be found and became the subject of a numerous patent applications [16-21]. The results of experimental studies carried out using of various impregnating substances were presented also in earlier works [22-24].
In this article, we describe the results of investigations concerning a new type of impregnation substance-carbon in the amorphous form. Other forms of carbon (graphite) is often used as a solid lubricant in grinding technology, which was widely presented in numerous works [25-31], because of its properties, as shown in the work [32]. In crystals of graphite, carbon atoms in one plane are linked by strong atomic bonds while in a plane perpendicular to it, the bonds are much weaker, Van der Waals type. This means that the graphite is soft and splintery making it a good lubricant, which was confirmed by Pierson in the work [32]. The amorphous carbon, like the graphite, is characterized by low reactivity and authors proposed the use of this variety of coal as an impregnating substance. The conducted experimental studies, the results of which were published in the work of Nadolny et al. [33], show that the use of amorphous carbon as an impregnating substance effectively impact on limitation of share of cloggings GWAS after grinding process of hard-to-cut materials. However, to determine the basic phenomena of physical and chemical nature that determine the obtained favorable effect, it was necessary to carry out detailed analysis of the composition of elements remaining after grinding on the GWAS. For this purpose, the scanning electron microscope (SEM) combined with energy-dispersive X-ray spectroscope (EDS) techniques were used and this article provides a wide set of analysis obtained as well as their analysis.

\section{Methodology of experimental studies}

\subsection{Main goal and basic assumptions}

The aim of this study was to precise identify composition of the elements and their participation on the amorphous carbontreated GWAS after grinding process of the Titanium Grade $2^{\circledR}$ alloy. To obtain this goal a representative sample of active surface of 1-35 × $10 \times 10-\mathrm{SG} / \mathrm{F} 46 \mathrm{G} 10 \mathrm{VTO}$ grinding wheel was selected and examined with the use of advanced SEM-EDS techniques. Examined fragment represented approximately one fifth of the wheel circumference. For the surface EDS analysis, three areas of this GWAS fragment were randomly selected.

\subsection{Grinding wheels}

Grinding wheel type 1 was made from microcrystalline sintered corundum (sol-gel alumina) $\mathrm{SG}^{\mathrm{TM}}$ abrasive grains number 46 and a special glass-crystalline bond, presented by Herman and Markul [34, 35]. The general description of the grinding wheel used in the experimental studies is given in Table 1 . 
Table 1 General description of grinding wheel used in the experiments

\begin{tabular}{|c|c|}
\hline Technical designation & $1-35 \times 10 \times 10-\mathrm{SG} / \mathrm{F} 46 \mathrm{G} 10 \mathrm{VTO}$ \\
\hline Grinding wheel type & 1 - flat grinding wheel \\
\hline Dimensions & $\begin{array}{l}\text { External diameter } d_{s}=35 \mathrm{~mm} \text {, width } \\
\qquad \begin{array}{l}b_{s}=10 \mathrm{~mm} \text {, inner diameter } \\
h_{s}=10 \mathrm{~mm}\end{array}\end{array}$ \\
\hline Abrasive grain type & $\begin{array}{l}\text { Microcrystalline sintered corundum } \\
\text { (sol-gel alumina) } \mathrm{SG}^{\mathrm{TM}} \text { by Norton (USA) }\end{array}$ \\
\hline Abrasive grain fracture no. & 46 \\
\hline Hardness class & G \\
\hline Structure no. & 10 \\
\hline Bond & Vitrified (glass-crystalline) \\
\hline Volume of grains $\left(V_{g}\right)$ & $42.0 \%$ \\
\hline Volume of bond $\left(V_{b}\right)$ & $11.5 \%$ \\
\hline Volume of pores $\left(V_{p}\right)$ & $46.5 \%$ \\
\hline
\end{tabular}

\subsection{Grinding wheel impregnation process}

Grinding wheels used for the investigations were modified by a process of impregnate using amorphous carbon as an impregnating substance. Carbon in the amorphous form was introduced into the grinding wheel body by thermal decomposition of organic compounds, in the case carbohydrates, according to the author's method described in the patent application no. P. 395441 [36]. In this method of impregnation of abrasive tools with vitrified bond, the grinding wheel is saturated with molten or dissolved organic compound in the form of a carbohydrate or an organic acid. The next process step consists in calcining without air, causing decomposition of the introduced compound with separation and deposition of carbon in the pores of the impregnated wheel. Time of impregnation

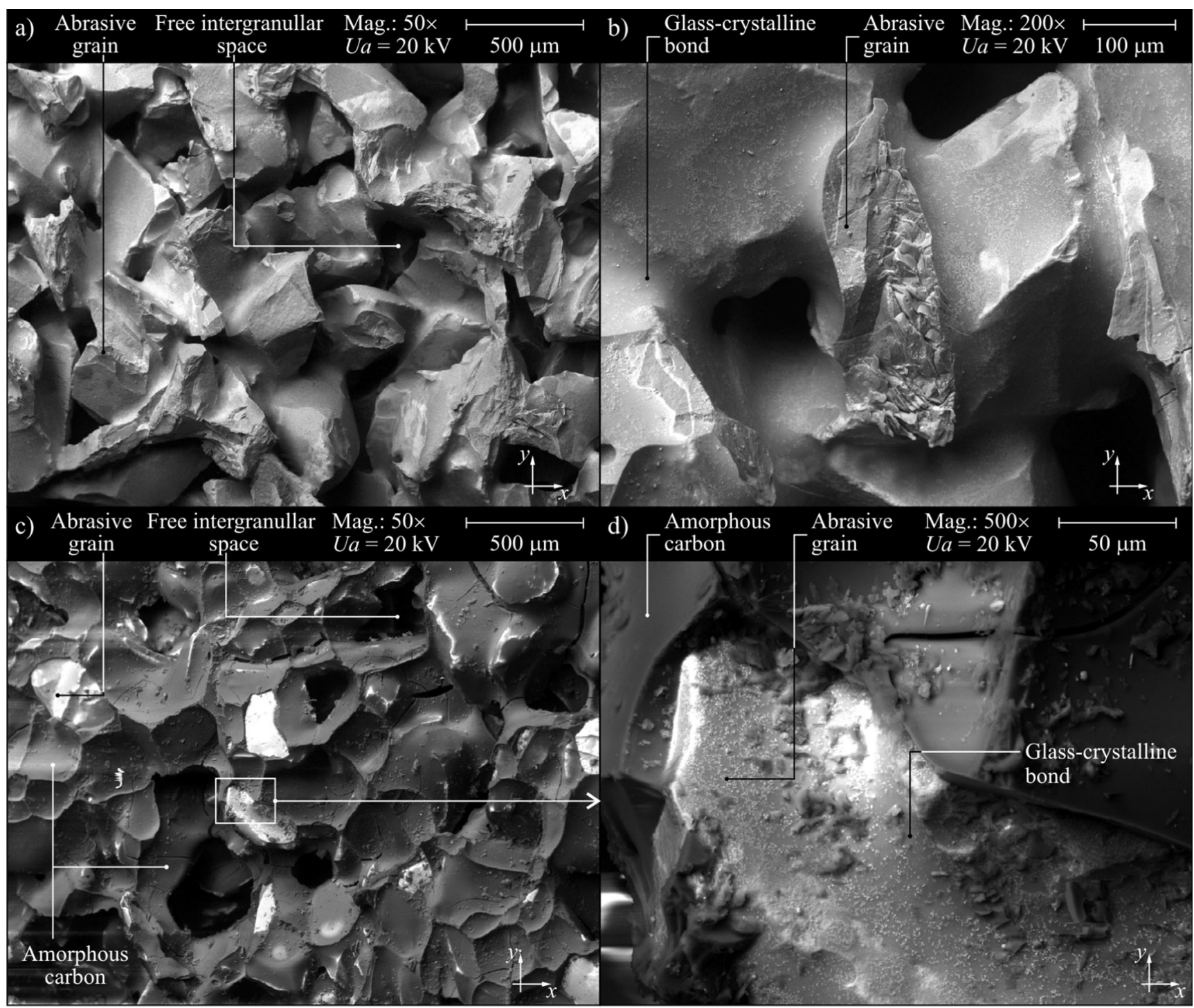

Fig. 1 SEM micrographs of the GWAS 1-35 × $10 \times 10-$ SG/F46G10VTO obtained by the use of JSM-5500LV SEM microscope produced by JEOL Ltd., before $(\mathbf{a}, \mathbf{b})$ and after the introduction an amorphous carbon impregnating substance $(\mathbf{c}, \mathbf{d})$ 
process conducted using proposed method directly depends on the mass of the substrate which undergoes decomposition. Calcination process is carried out to complete decomposition of the substrate. In the case of described impregnation process of grinding wheels, the approximate time of impregnation was about $60 \mathrm{~min}$.

In Fig. 1, SEM micrographs of the GWAS with microcrystalline sintered corundum abrasive grains and glasscrystalline bond before (Fig. 1a, b) and after the introduction an amorphous carbon impregnating substance (Fig. 1c, d) were presented. In Fig. 1a (size $=2.55 \times 1.91 \mathrm{~mm}$, mag. $50 \times$ ) and Fig. $1 \mathrm{~b}$ (size $=0.64 \times 0.48 \mathrm{~mm}$, mag. $200 \times$ ) is clearly visible a clean (non covered) grinding wheel structure with its characteristic components. The result of impregnation process (layer of an amorphous carbon is visible as a dark gray areas) can be observed in Fig. 1c $($ size $=2.55 \times 1.91 \mathrm{~mm}$, mag. $50 \times)$ as well as in higher magnification in more details in Fig. 1d (size: $0.25 \times 0.19 \mathrm{~mm}$, mag. 500×).

During preparation of the grinding wheel for work, weight gain resulting from the introduction of impregnate in the form of amorphous carbon into tool body was also measured. The measurement results were given in Table 2.

During dressing, carbon layer is removed from the abrasive grain vertexes but it is still present in the free intergranular spaces. Applied impregnation method provides applying to the grinding wheel active surface a carbon layer having a thickness of about $20 \mu \mathrm{m}$ [33].

\subsection{Workpiece material}

The experimental studies were carried out using Titanium Grade $2^{\circledR}$ as workpiece material. This alloy was selected from so-called hard-to-cut materials because of it properties, like high ductility and elasticity, small thermal conductivity, as well as propensity to temperature strengthening during machining. Titanium Grade $2^{\circledR}$ is one of the most widely used titanium alloys. It is highly corrosion resistant, perfectly weldable, and does not lose its structure $\alpha$ after heat treatment. It is widely used in the construction of drilling platforms, chemical industry devices, and in the production of various types of apparatus [1]. The

Table 2 Changes in the weight of the grinding wheels due to the impregnation process

\begin{tabular}{llll}
\hline Grinding wheel & $\begin{array}{l}\text { Weight before } \\
\text { treatment }\end{array}$ & $\begin{array}{l}\text { Weight after } \\
\text { treatment }\end{array}$ & $\begin{array}{l}\text { The increase } \\
\text { in mass }\end{array}$ \\
\hline $\begin{array}{l}\text { Amorphous carbon-treated } \\
\text { grinding wheel }\end{array}$ & $17.23 \mathrm{~g}$ & $18.28 \mathrm{~g}$ & $6.09 \%$ \\
\hline
\end{tabular}

Table 3 Chemical composition of the Titanium Grade $2^{\circledR}$ alloy [1]

\begin{tabular}{|c|c|c|c|}
\hline Material & $\begin{array}{l}\text { Material } \\
\text { no. }\end{array}$ & Standard & $\begin{array}{l}\text { Chemical composition } \\
\text { and percentage of elements }\end{array}$ \\
\hline $\begin{array}{l}\text { Titanium } \\
\text { Grade } 2^{(\circledR *}\end{array}$ & 3.7035 & $\begin{array}{l}\text { UNS R50400 } \\
\text { ASTM B861 }\end{array}$ & $\begin{array}{l}\mathrm{C}(0.08)+\mathrm{Fe}(0.25) \\
\quad+\mathrm{O}(0.25 \max )+\mathrm{Ni}(0.03) \\
\quad+\mathrm{H}(0.015 \max )+\mathrm{Ti} \\
\quad \text { (Balance) }\end{array}$ \\
\hline
\end{tabular}

* Material is produced by Special Metals Corporation (USA) and distributed by Bibus Metals (Switzerland)

characteristics of the used workpiece material was given in Tables 3 and 4.

\subsection{Grinding process conditions}

Grinding tests were carried out using an experimental position built upon the basis of an universal grinding machine RUP 28P (Mechanical Works Tarnow SA, Tarnow, Poland) equipped with a high-speed spindle EV-70/70-2WB (FISHER Spindle Group AG, Herzogenbuchsee, Switzerland). A detailed description of grinding conditions, including scheme of process kinematics, used the parameters of dressing cut, and grinding process were shown in Table 5.

\subsection{Observation-measurement methods and systems}

In order to achieve the main goals of experimental studies in a wide range of the SEM-EDS observations and measurements, a proper research apparatus was selected. The SEM imaging and observation of selected fragments of

Table 4 Physical properties of the Titanium Grade $2^{\circledR}$ alloy [1]

\begin{tabular}{ll}
\hline Parameter name & Titanium Grade ${ }^{\circledR}$ \\
\hline Density & $4.51 \mathrm{~g} \mathrm{~cm}^{-3}$ \\
Hardness, Knoop & 170 \\
Hardness, Rockwell B & 80 \\
Hardness, Vickers & 145 \\
Tensile strength, ultimate & $344 \mathrm{MPa}$ \\
Tensile strength, yield & $275-410 \mathrm{MPa}$ \\
Elongation at break & $20 \%$ \\
Reduction of area & $35 \%$ \\
Modulus of elasticity (in tension) & $105 \mathrm{GPa}$ \\
Compressive modulus & $110 \mathrm{GPa}$ \\
Poisson's ratio & 0.37 \\
Izod impact & $114-171 \mathrm{~J}^{-1}$ \\
Fatigue strength (1E +7 cycles, unnotched) & $300 \mathrm{MPa}$ \\
Fatigue strength (30,000 cycles, unnotched) & $425 \mathrm{MPa}$ \\
Fracture toughness (K(Q); annealed) & $66 \mathrm{MPa} \mathrm{m}{ }^{1 / 2}$ \\
Shear modulus & $45 \mathrm{GPa}^{-1} \mathrm{~K}^{-1}$ \\
Thermal conductivity & $16.4 \mathrm{~W} \mathrm{~m}$ \\
\hline
\end{tabular}


Table 5 Description of grinding conditions

\begin{tabular}{|c|c|}
\hline Grinding process & $\begin{array}{lll}\text { Reciprocal peripheral internal cylindrical grinding } & \text { Cross-section } \\
\text { of machining layer }\end{array}$ \\
\hline Grinding machine & $\begin{array}{l}\text { Universal grinding machine: RUP 28P (Mechanical Works Tarnow SA, Tarnow, Poland), } \\
\text { High-speed spindle: EV-70/70-2WB (FISHER Spindle Group AG, Herzogenbuchsee, } \\
\text { Switzerland) with max. rotation } 60,000 \mathrm{~min}^{-1} \text {, power of machine cutting } 5.2 \mathrm{~kW}\end{array}$ \\
\hline Grinding wheel & $1-35 \times 10 \times 10-\mathrm{SG} / \mathrm{F} 46 \mathrm{G} 10 \mathrm{VTO}$ \\
\hline $\begin{array}{l}\text { Grinding wheel } \\
\text { dressing parameters }\end{array}$ & $\begin{array}{l}\text { Dresser: single grain diamond dresser with mass: } Q_{d}=1.25 \mathrm{kt} \text {, } \\
\text { Grinding wheel rotational speed while dressing: } n_{s d}=10,000 \mathrm{~min}^{-1} \\
\text { Dressing allowance: } a_{d}=0.0125 \mathrm{~mm} \\
\text { Axial table feed speed while dressing: } v_{f d}=10 \mathrm{~mm} \cdot \mathrm{s}^{-1} \\
\text { Number of dressing passes: } i_{d}=6\end{array}$ \\
\hline $\begin{array}{l}\text { Grinding } \\
\text { parameters }\end{array}$ & $\begin{array}{l}\text { Grinding wheel peripheral speed: } v_{s}=18 \mathrm{~m} \cdot \mathrm{s}^{-1} \\
\text { Axial table feed speed: } v_{f a}=20 \mathrm{~mm} \cdot \mathrm{s}^{-1} \\
\text { Total working engagement (machining allowance): } a_{e} \text { tot }=0.15 \mathrm{~mm} \\
\text { Workpiece peripheral speed: } v_{w}=1.1 \mathrm{~m} \cdot \mathrm{s}^{-1} \\
\text { Grinding time } t_{g}=90 \mathrm{~s} \text { (for single machined opening) } \\
\text { Grinding fluid flow rate: } Q_{G F}=4.0 \mathrm{~L} \cdot \mathrm{min}^{-1}\end{array}$ \\
\hline Grinding fluid & $\begin{array}{l}5 \% \text { water solution of Syntilo RHS (Castrol, Liverpool, Great Britain) oil given by flood } \\
\text { method }\end{array}$ \\
\hline Workpieces & $\begin{array}{l}\text { Internal cylindrical surface of rings, made of Titanium Grade } 2^{\circledR} \text { alloy, } \\
\text { internal diameter: } d_{w}=56 \mathrm{~mm} \text {, width: } b_{w}=20 \mathrm{~mm}\end{array}$ \\
\hline
\end{tabular}

active surface of $1-35 \times 10 \times 10-S G / F 46 G 10$ VTO grinding wheel was mainly carried out by use of two advanced microscopy systems: JSM-5500LV (JEOL Ltd., Tokyo, Japan) and Auriga ${ }^{\circledR}$ (Carl Zeiss Microscopy GmbH,

Table 6 Characteristics of observation-measurement systems used in the experimental studies

\begin{tabular}{|c|c|c|c|c|}
\hline No. & Instrument type & Model & Producer & Configuration and features \\
\hline 1. & SEM microscope & $\begin{array}{l}\text { JSM- } \\
\text { 5500LV }\end{array}$ & JEOL Ltd. (Tokyo, Japan) & $\begin{array}{l}\text { Components: detectors: SEI, BEI, specimen stage: eucentric goniometer } \\
\text { Features: magnification range }=18-300,000 \times \text { (in } 136 \text { steps), vacuum } \\
\text { pressure in the specimen chamber: } 10-270 \mathrm{~Pa} \text { (lowest } 1 \mathrm{~Pa}) \text {, accelerating } \\
\text { voltage }=0.5-30 \mathrm{kV}(53 \mathrm{steps}) \text {, resolution: for SEI (using HVM) } 4.0 \mathrm{~nm} \\
(\mathrm{AV}=30 \mathrm{kV} \text {, WD }=6 \mathrm{~mm}) \text {, for BEI (using LVM) } 5.0 \mathrm{~nm}(\mathrm{AV}=30 \mathrm{kV} \text {, } \\
\mathrm{WD}=8 \mathrm{~mm}) \text { at an adjustable pressure of } 10 \text { to } 270 \mathrm{~Pa} \text {, evacuation time: for } \\
\text { HVM approx. } 100 \mathrm{~s} \text {, for LVM approx. } 90 \mathrm{~s} \\
\text { Software: dedicated JEOL software }\end{array}$ \\
\hline 2. & $\begin{array}{l}\text { SEM-FIB } \\
\text { CrossBeam }^{\circledR} \\
\text { workstation }\end{array}$ & Auriga $^{\circledR}$ & $\begin{array}{l}\text { Carl Zeiss Microscopy GmbH } \\
\text { (Jena, Germany) }\end{array}$ & $\begin{array}{l}\text { Components: GEMINI }{ }^{\circledR} \text { column (SEM), Cobra column (FIB), detectors: SE } \\
\quad \text { (in-lens), Everhart-Thornley SE + SESI (chamber), specimen chamber with } \\
15 \text { accessory ports, specimen stage: } 6 \text {-axis super eucentric motorized stage } \\
\text { Features }(\text { SEM): magnification range }=12-1,000,000 \times \text {, accelerating voltage } \\
\quad=0.1-30 \mathrm{kV} \text {, resolution }(\mathrm{SEM})=1.0 \mathrm{~nm}(\mathrm{AV}=15 \mathrm{kV}) \text { and } 1.9 \mathrm{~nm} \\
(\mathrm{AV}=1 \mathrm{kV}) \\
\text { Software: } \text { SmartSEM }^{\circledR}\end{array}$ \\
\hline 3. & $\begin{array}{l}\text { SDD series EDS } \\
\text { detector }\end{array}$ & Octane plus & $\begin{array}{l}\text { EDAX, Inc. (Mahwah, } \\
\text { NJ, USA) }\end{array}$ & $\begin{array}{l}\text { Features: active surface: up to } 100 \mathrm{~mm}^{2} \text {, count rates: up to } 1.6 \mathrm{Mcps} / 800 \mathrm{kcps} \text {, } \\
\text { resolution }=123 \mathrm{eV} \text {, Peak stability }=<1 \mathrm{eV} \text { up to } 100 \mathrm{kcps} \\
\text { Software: TEAM }{ }^{\mathrm{TM}} \mathrm{EDS} \text { software suite }\end{array}$ \\
\hline
\end{tabular}




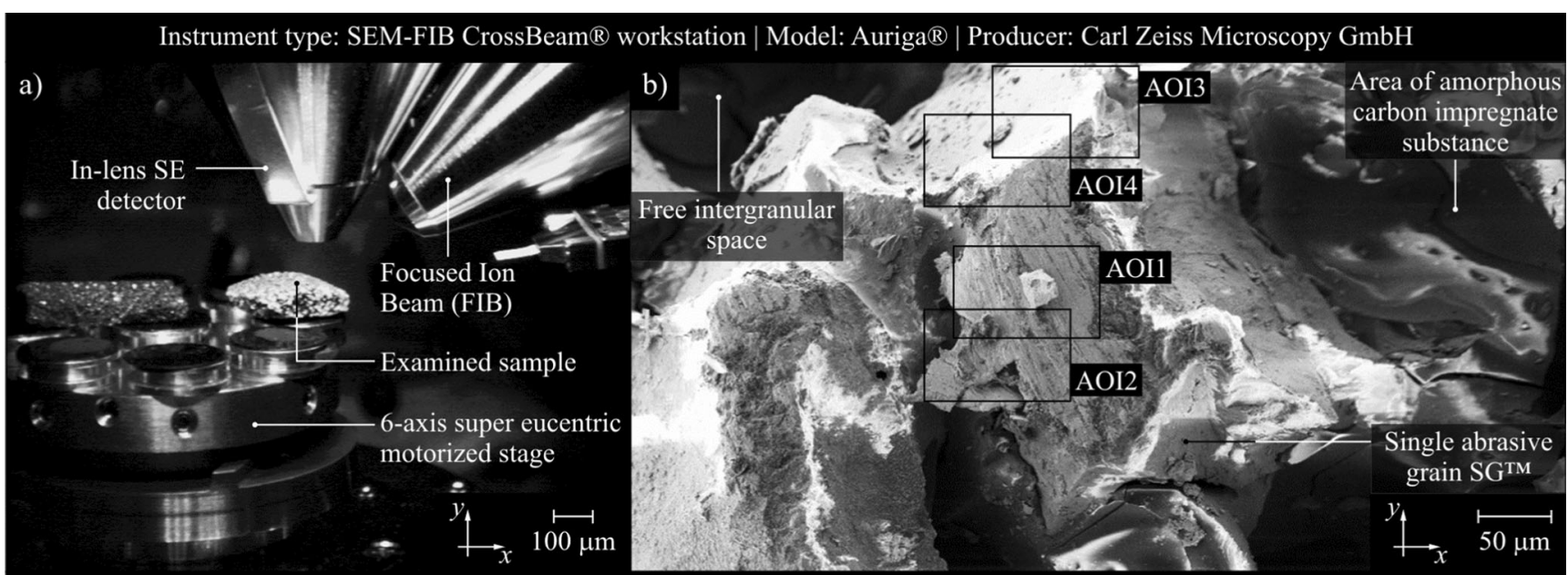

Magnification: $99 \times \mid$ Acc. voltage: $0 \mathrm{kV} \mid$ Signal A: TV | WD: $1.3 \mathrm{~mm}$ | FIB mode: imaging

Magnification: $287 \times \mid$ Acc. voltage: $10 \mathrm{kV} \mid$ Image size: $0.64 \times 0.33 \mathrm{~mm} \mid$ Signal A: SESI | WD: $4.1 \mathrm{~mm}$ | FIB mode: imaging

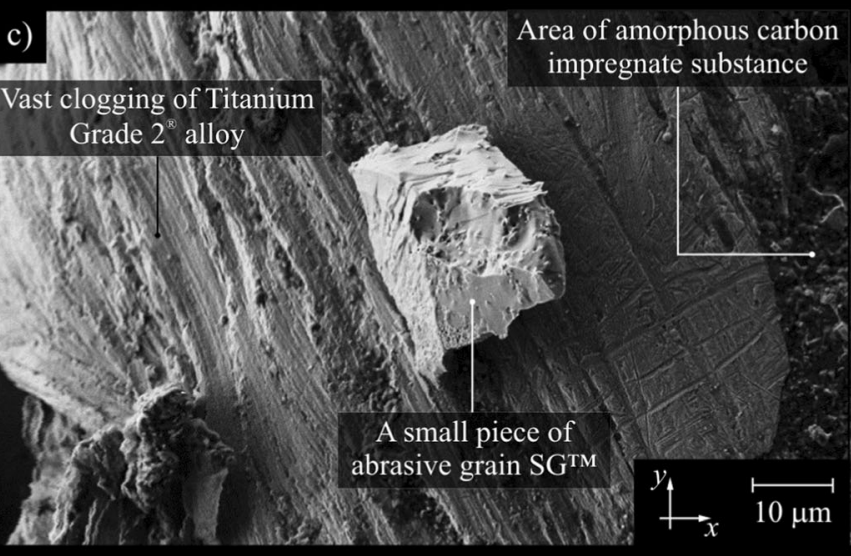

AOI: 1 | Magnification: $2000 \times$ | Acc. voltage: $10 \mathrm{kV} \mid$ Image size: $0.10 \times 0.06 \mathrm{~mm} \mid$ Signal A: SESI | WD: $4.0 \mathrm{~mm}$ | FIB mode: imaging

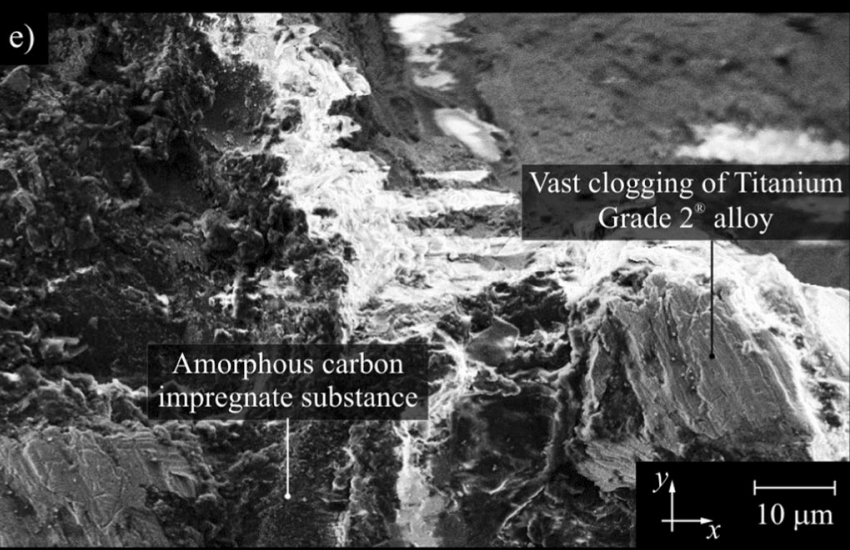

AOI: 3 | Magnification: $2000 \times$ | Acc. voltage: $10 \mathrm{kV}$ | Image size: $0.10 \times 0.06 \mathrm{~mm} \mid$ Signal A: SESI | WD: $4.0 \mathrm{~mm} \mid$ FIB mode: imaging

Fig. 2 Collection of selected results obtained for the amorphous carbon impregnated GWAS 1-35 × $10 \times 10$-SG/F46G10VTO after the reciprocal internal cylindrical grinding of Titanium Grade $2^{\circledR}$ alloy (sample 1 ) by the use of Auriga ${ }^{\circledR}$ SEM-FIB CrossBeam ${ }^{\circledR}$ produced by Carl Zeiss Microscopy $\mathrm{GmbH}$ : a detailed view of vacuum chamber of the main instrument; b SEM micrograph $($ size $=0.64 \times 0.33 \mathrm{~mm}$, mag. $287 \times)$ of

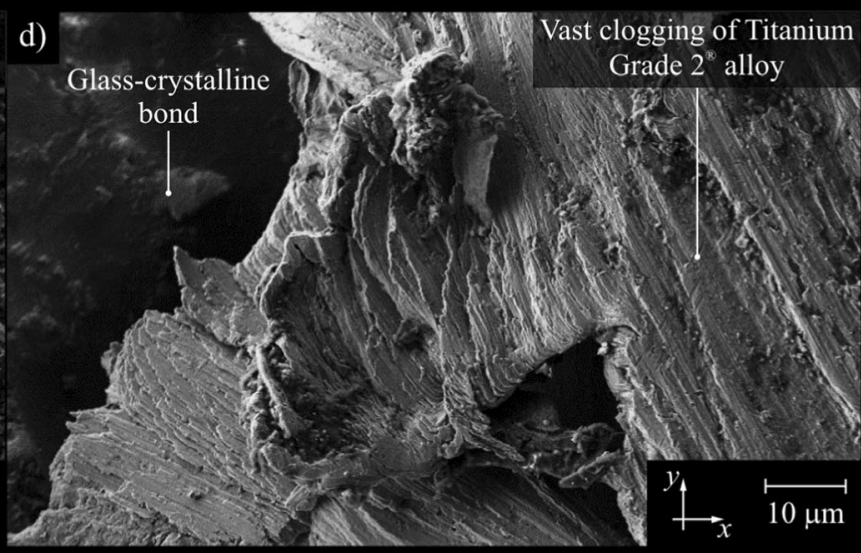

AOI: 2 | Magnification: $2000 \times \mid$ Acc. voltage: $10 \mathrm{kV}$ | Image size: $0.10 \times 0.06 \mathrm{~mm} \mid$ Signal A: SESI | WD: $4.1 \mathrm{~mm} \mid$ FIB mode: imaging

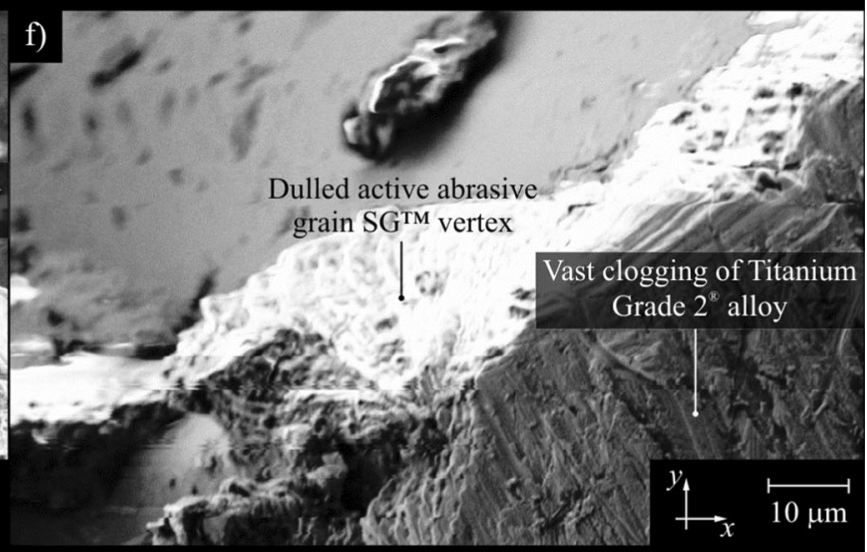

AOI: 4 | Magnification: $2000 \times \mid$ Acc. voltage: $10 \mathrm{kV}$ | Image size: $0.10 \times 0.06 \mathrm{~mm} \mid$ Signal A: SESI | WD: $4.1 \mathrm{~mm} \mid$ FIB mode: imaging

a vast panorama of examined GWAS with marked four AOI's; c SEM micrograph (size $=0.10 \times 0.06 \mathrm{~mm}$, mag. $2000 \times$ ) of AOI 1 extracted from Fig. $2 b$; d SEM micrograph (size $=0.10 \times 0.06 \mathrm{~mm}$, mag. $2000 \times$ ) of AOI 2 extracted from Fig. 2b. e) SEM micrograph (size $=0.10 \times 0.06 \mathrm{~mm}$, mag. 2000 $\times$ ) of AOI 3 extracted from Fig. 2b, f) SEM micrograph $($ size $=0.10 \times 0.06 \mathrm{~mm}$, mag. $2000 \times)$ of AOI 4 extracted from Fig. $2 \mathrm{~b}$ 
Jena, Germany). During EDS measurements, the Octane plus (EDAX, Inc., Mahwah, NJ, USA) - a high accuracy silicon drift detector (SSI) was used. The main part of the studies were carried out in laboratories of the Institute of Surface and Thin Film Technology, University of Applied Sciences Technology, Business and Design (Wismar, Germany), whereas the additional works were carried out in the Laboratory of Electron Microscopy and the Structural Research, Central Laboratory of the Faculty of Technology and Education, Koszalin University of Technology (Koszalin, Poland). The detailed information related with research apparatus used in the experimental studies are given in Table 6.

\section{Results and discussion}

General results of the grinding process (surface roughness parameters, grinding power, and analysis of the GWAS cloggings after grinding) were described in one of the earlier works of the authors [33]. At this point, the results of detailed SEM-EDS analysis of the amorphous carbon impregnated active surface of $1-35 \times 10 \times 10-S G / F 46 G 10$ VTO grinding wheel after the reciprocal internal cylindrical grinding of Titanium Grade $2^{\circledR}$ alloy were given. In Fig. 2, the collection of selected SEM micrographs obtained by the use of Auriga ${ }^{\circledR}$ SEM-FIB CrossBeam ${ }^{\circledR}$ produced by Carl Zeiss Microscopy $\mathrm{GmbH}$ for one of the two analyzed fragments of the above-

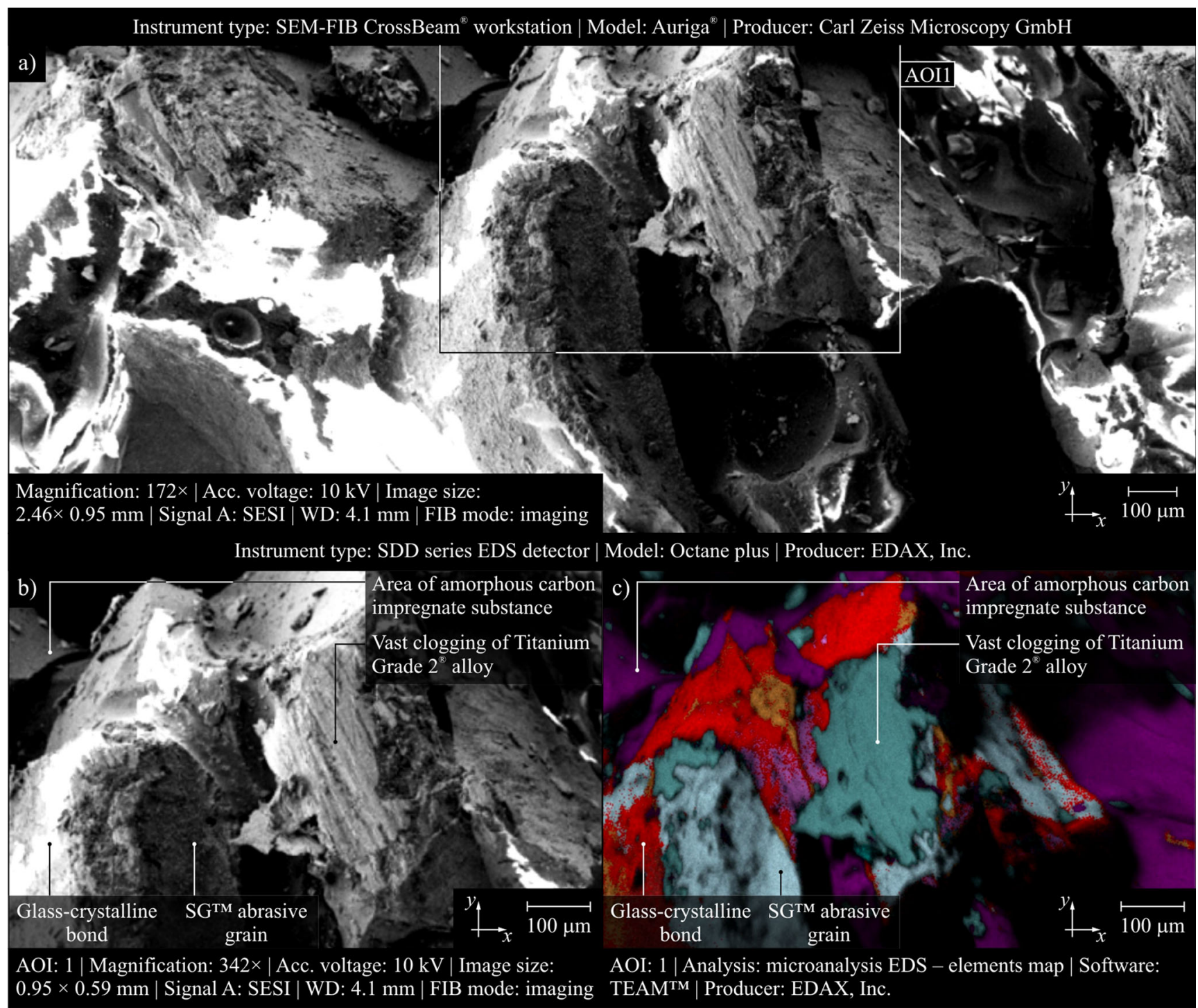

Fig. 3 Collection of selected results obtained for the amorphous carbon impregnated GWAS $1-35 \times 10 \times 10-$ SG/F46G10VTO after the reciprocal internal cylindrical grinding of Titanium Grade $2^{\circledR}$ alloy (Sample 1) by the use of Auriga ${ }^{\circledR}$ SEM-FIB CrossBeam ${ }^{\circledR}$ workstation produced by Carl Zeiss Microscopy $\mathrm{GmbH}$ and Octane plus EDS detector produced by

EDAX, Inc.: a SEM micrograph (size $=2.46 \times 0.95 \mathrm{~mm}$, mag. $172 \times$ ) of a vast panorama of examined GWAS with marked AOI 1; b SEM micrograph (size $=0.95 \times 0.59 \mathrm{~mm}$, mag. $342 \times)$ of AOI 1 extracted from Fig. 3a; c microanalysis EDS - elements map of the AOI 1 with visible a vast clogging of the Titanium Grade $2^{\circledR}$ alloy 


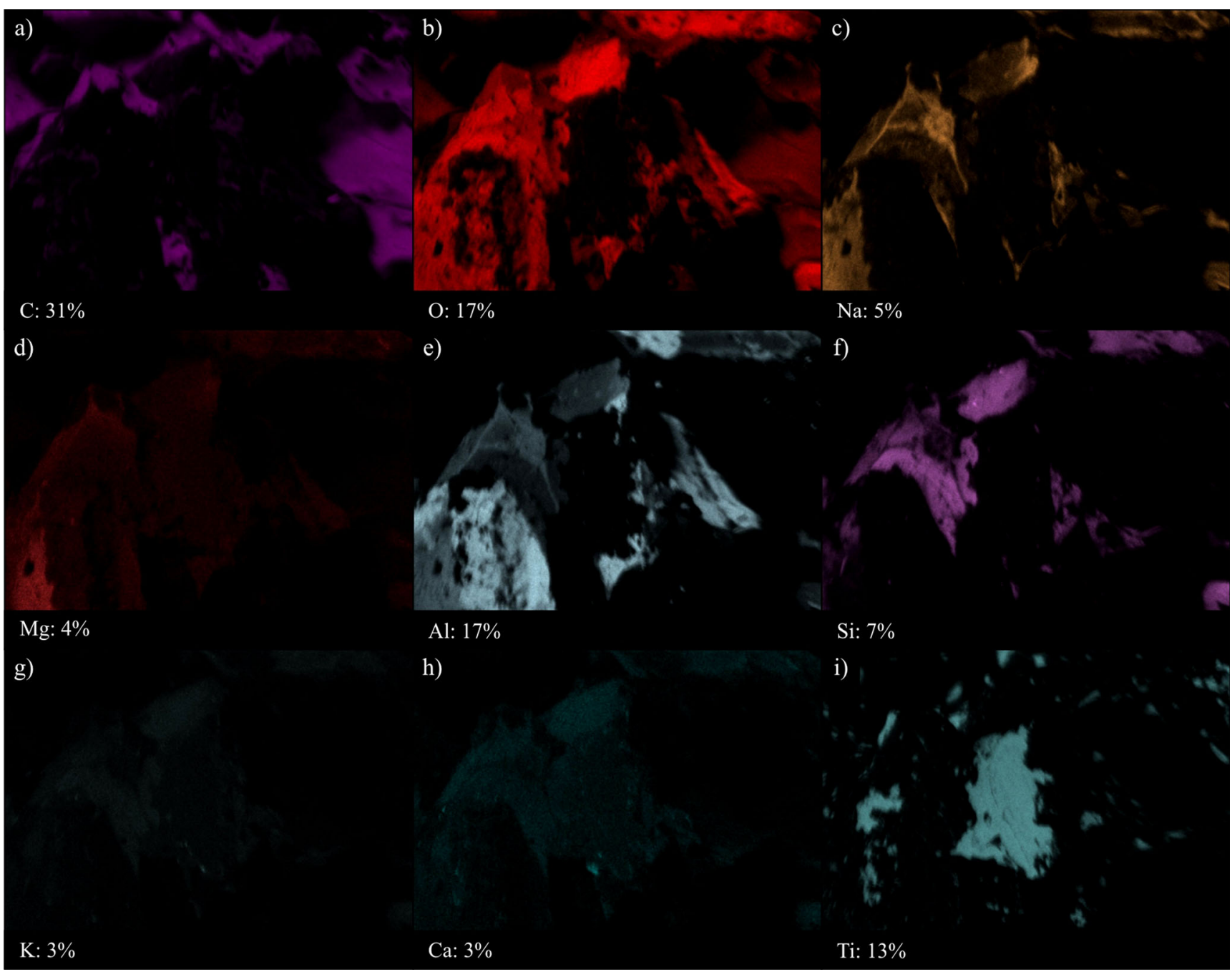

Fig. 4 Individual elements and their percentage extracted from element map (Fig. 3c) obtained by the use of TEAM ${ }^{\mathrm{TM}}$ software by EDAX, Inc.: a carbon; b oxygen; c sodium; d magnesium; e aluminum; f silicon; $\mathbf{g}$ potassium; $\mathbf{h}$ calcium; $\mathbf{i}$ titanium

mentioned abrasive tool placed in a vacuum chamber (Fig. 2a) and marked as sample 1, were presented. The output SEM micrograph $($ size $=0.64 \times 0.33 \mathrm{~mm}$, mag. $287 \times)$ show vast panorama of examined GWAS with centrally located a single abrasive grain $\mathrm{SG}^{\mathrm{TM}}$ clogged by the machined material (Fig. 2b). On this relatively large-sized clogging (area $=31.48 \mathrm{~mm}^{2}$, perimeter $=0.85 \mathrm{~mm}$, length $=0.26 \mathrm{~mm}$, width $=0.17 \mathrm{~mm}$ ), four areas of interest (AOI) were marked. The detailed SEM imaging of those AOIs were presented in Fig. 2c, f. AOI 1 ( size $=0.10 \times 0.06 \mathrm{~mm}$, mag. 2000 $\times$ ) shows a situation where a small piece of a single abrasive grain $\mathrm{SG}^{\mathrm{TM}}($ size $=0.023 \times 0.014 \times 0.003 \mathrm{~mm})$ were
Fig. 5 EDS spectrum with an elements contained in the analyzed amorphous carbon impregnated GWAS $1-35 \times 10 \times 10-$ SG/F46G10VTO after the reciprocal internal cylindrical grinding of Titanium Grade $2^{\circledR}$ alloy by the use of Octane plus EDS detector produced by EDAX, Inc. for Sample 1, AOI 1

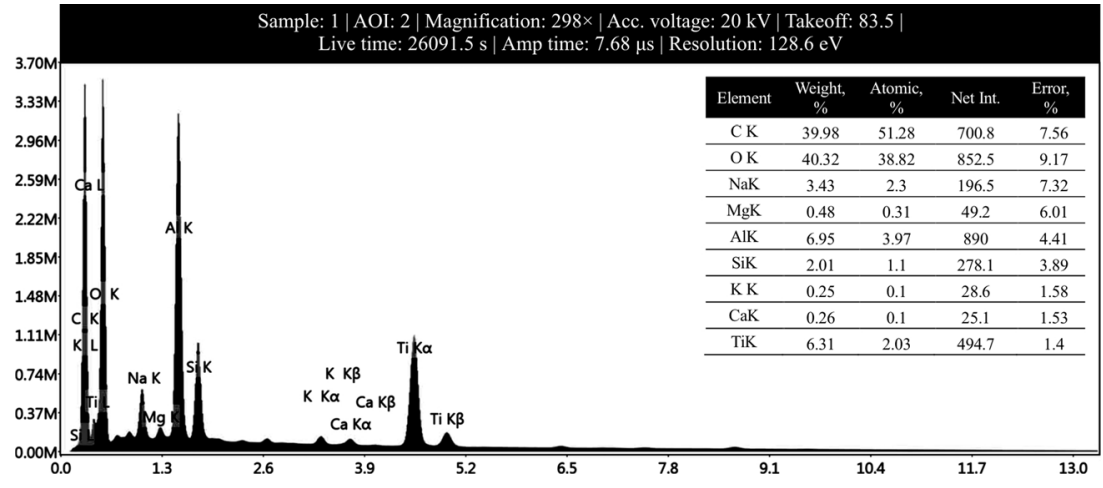


torn out from the abrasive tool during grinding process of hard-to-cut Titanium Grade $2^{\circledR}$ and connected with the clogging of its alloy formed on the GWAS (Fig. 2c). Detailed view of the upper (AOI 2) and lower (AOI 3) fragment of the vast clogging area was presented in Fig. $2 \mathrm{~d}$, e $($ size $=0.10 \times 0.06 \mathrm{~mm}$, mag. $2000 \times)$, respectively. Figure $2 \mathrm{f}($ size $=0.10 \times 0.06 \mathrm{~mm}$, mag. $2000 \times)$ presents this same upper fragment of the vast clogging area (AOI 4) with a clearly visible details of relatively long and flat dulled active abrasive grain $\mathrm{SG}^{\mathrm{TM}}$ vertex.

For EDS analysis, a fragment of the GWAS $($ size $=2.46 \times 0.95 \mathrm{~mm}$, mag. $172 \times)$ presented in Fig. $3 \mathrm{a}$ was selected. From this fragment, an AOI 1 $($ size $=0.95 \times 0.59 \mathrm{~mm}$, mag. $342 \times)$ was extracted, interesting due to the fact, that included a relatively vast clogging of Titanium Grade $2^{\circledR}$ alloy located in a center of marked AOI (Fig. 3b). For the AOI 1, the microanalysis EDS (Fig. 3c) by the use of TEAM ${ }^{\mathrm{TM}}$ software (EDAX, Inc., Mahwah, NJ, USA) was carried out. During microanalysis EDS, a Smart Element Mapping module of the TEAM ${ }^{\mathrm{TM}}$ software was used for precise identifying composition of the elements and their percentage in selected fragment of the GWAS. The obtained in an automatic mode elements map (Smart Element maps) was presented in Fig. 3c, whereas a percentage calculated for individual elements in Fig. 4. For the fast identification and location within the analyzed AOI, each element has been highlighted in a different color. A collection of such kind of results was presented in Fig. 4.

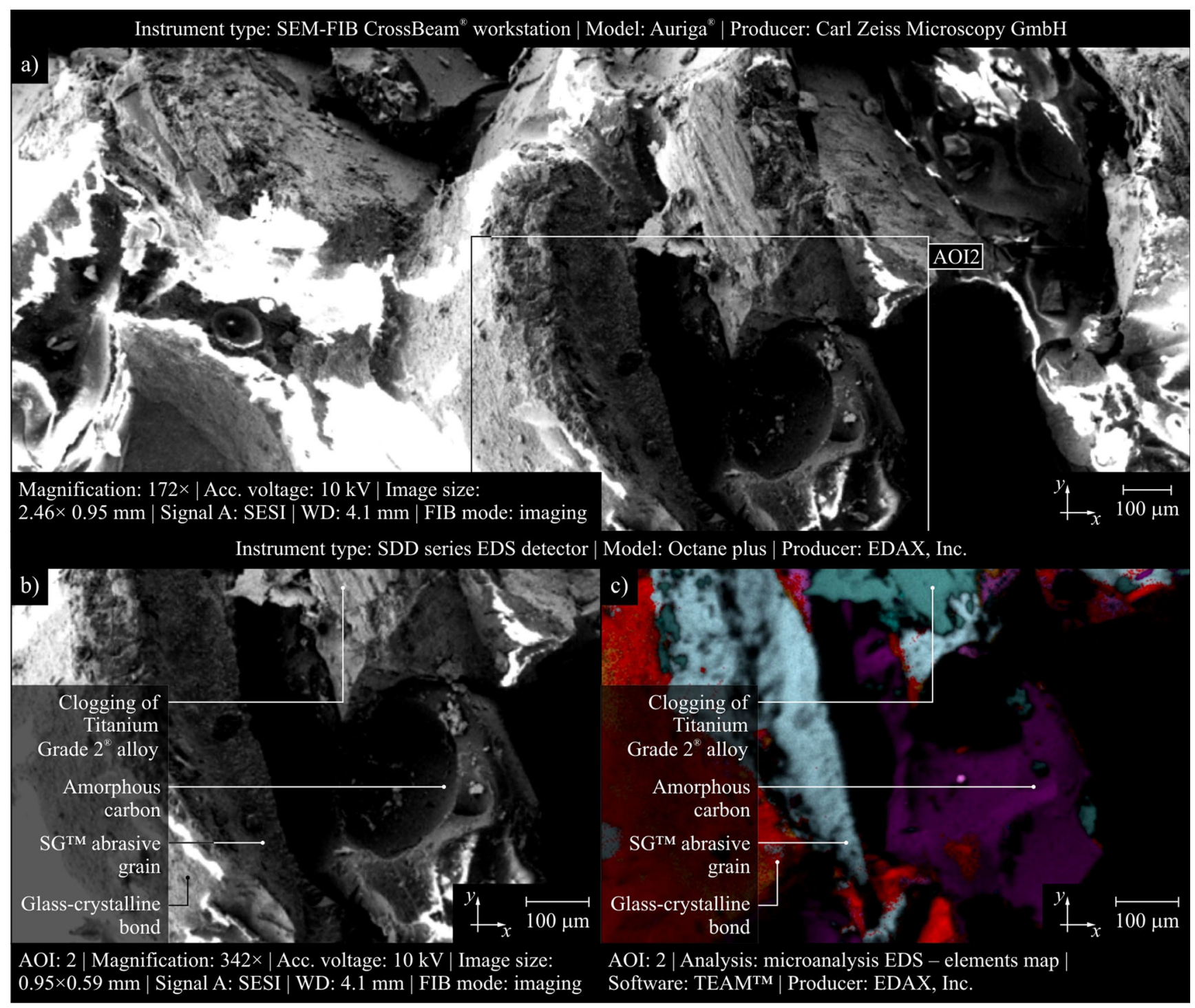

Fig. 6 Collection of selected results obtained for the amorphous carbon impregnated GWAS 1-35 × $10 \times 10$-SG/F46G10VTO after the reciprocal internal cylindrical grinding of Titanium Grade $2^{\circledR}$ alloy (sample 1) by the use of Auriga ${ }^{\circledR}$ SEM-FIB CrossBeam ${ }^{\circledR}$ workstation produced by Carl Zeiss Microscopy GmbH and Octane plus EDS detector produced by

EDAX, Inc.: a SEM micrograph $($ size $=2.46 \times 0.95 \mathrm{~mm}$, mag. $172 \times)$ of a vast panorama of examined GWAS with marked AOI 2; b SEM micrograph (size $=0.95 \times 0.59 \mathrm{~mm}$, mag. $342 \times)$ of AOI 2 extracted from Fig. 6a, c) microanalysis EDS - elements map of the AOI 2 with visible a vast clogging of the Titanium Grade $2^{\circledR}$ 
The analysis of Fig. 4 shows that in AOI 1, a large concentration of carbon (31\%), oxygen, and aluminum (both $17 \%$ ) as well as titanium (13\%) was observed. The concentration of the rest of elements was smaller and occurred in a range from 7 to $3 \%$. A high percentage of the amorphous carbon, highlighted by violet (Fig. 4a), on the GWAS indicate its relatively large concentration and even distribution even after the grinding process. A similar distribution was also observed for the aluminum, highlighted by blue (Fig. 4e), and silicon, highlighted by light violet (Fig. 4f). The distribution of titanium, highlighted by azure (Fig. 4i), was more uneven. On AOI 1 was clearly visible both a large concentration areas and a numerous of a small randomly located titanium-clogged areas. The analysis from the Fig. 4 closely correspond with EDS spectrum containing also an elemental composition of AOI 1 presented in Fig. 5. Fig. 6a presented the same, such as in Fig. 3a, fragment of the GWAS (size $=2.46 \times 0.95 \mathrm{~mm}$, mag. 172×). From this fragment, another AOI-AOI 2 $($ size $=0.95 \times 0.59 \mathrm{~mm}$, mag. $342 \times)$ was extracted, which presents a lower area (Fig. 6b) of the abrasive grain $\mathrm{SG}^{\mathrm{TM}}$ clogged by Titanium Grade $2^{\circledR}$ alloy from Fig. 3b. For this AOI 2, the microanalysis EDS (Fig. 6c) was also carried out. The procedure realized by the use of TEAM ${ }^{\mathrm{TM}}$ software was the same as in the previous analysis and include obtained in an automatic mode elements map with percentage calculated for individual elements (Fig. 7). In this case, a large concentration of aluminum ( $25 \%)$, carbon ( $21 \%)$, oxygen ( $17 \%)$, as well as titanium (11\%) was observed. The concentration of the rest of elements was smaller and occurred in a range from 9 to $4 \%$.

A percentage of the carbon, highlighted by violet (Fig. 7a), was $10 \%$ less than in AOI 1 (Figs. 3c, 4a), which confirms its even distribution. The significant presence of carbon indicates high efficiency of applying the method of impregnation, which allowed to introduction amorphous carbon to intergranular spaces in the whole volume of the vitrified grinding wheel. Even distribution of the impregnate is necessary for the proper operation of the grinding wheel, both to the balancing of the tools, as well as with regard to ensuring the

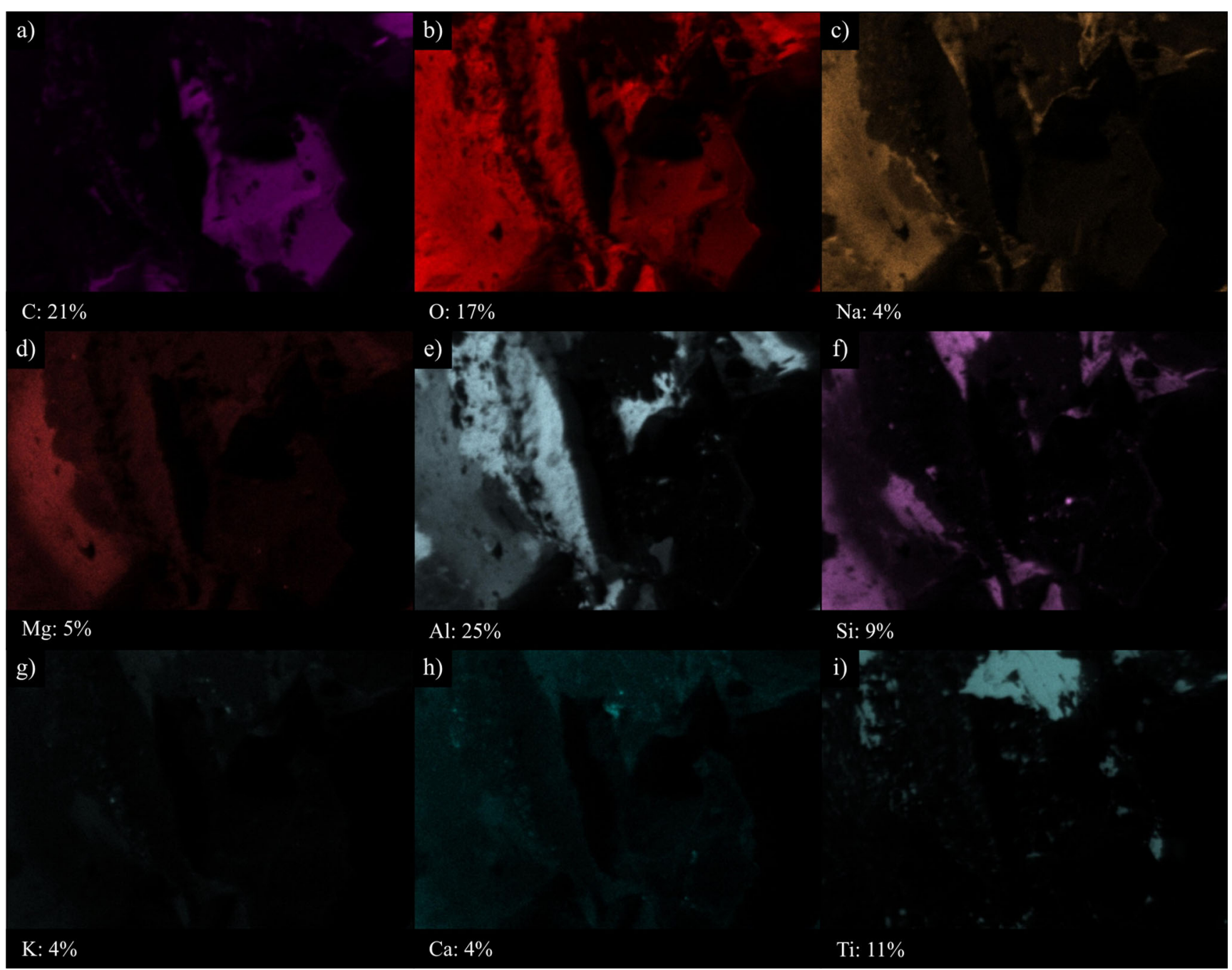

Fig. 7 Individual elements and their percentage extracted from element map (Fig. 6c) obtained by the use of TEAM ${ }^{\mathrm{TM}}$ software by EDAX, Inc.: a carbon; b oxygen; c sodium; $\mathbf{d}$ magnesium; e aluminum; f silicon; $\mathbf{g}$ potassium; $\mathbf{h}$ calcium; $\mathbf{i}$ titanium 
Fig. 8 EDS spectrum with an elements contained in the analyzed amorphous carbon impregnated GWAS

$1-35 \times 10 \times 10-$ SG/F46G10VTO after the reciprocal internal cylindrical grinding of Titanium Grade $2^{\circledR}$ alloy by the use of Octane plus EDS detector produced by EDAX, Inc. for Sample 1, AOI 2

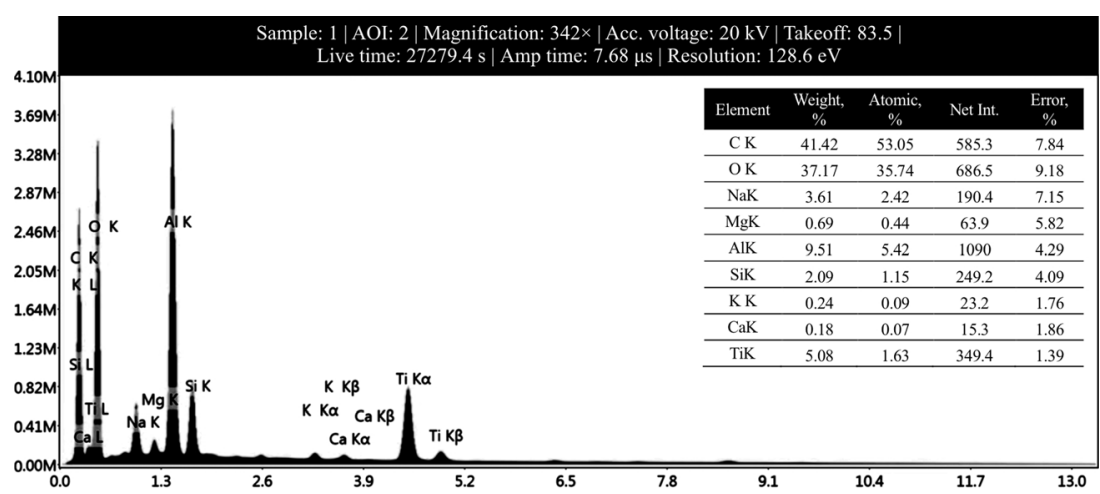

participation of impregnating substances in the grinding process, even after subsequent cycles of dressing. A similar distribution was also observed for the aluminum, highlighted by blue (Fig. 7e), and oxygen, highlighted by red (Fig. 7b). The distribution of titanium, highlighted by azure (Fig. 7i), was uneven and similar to distribution of this element presented for AOI 1 (Fig. 4i). The analysis from Fig. 7 closely correspond with EDS spectrum containing also an elemental

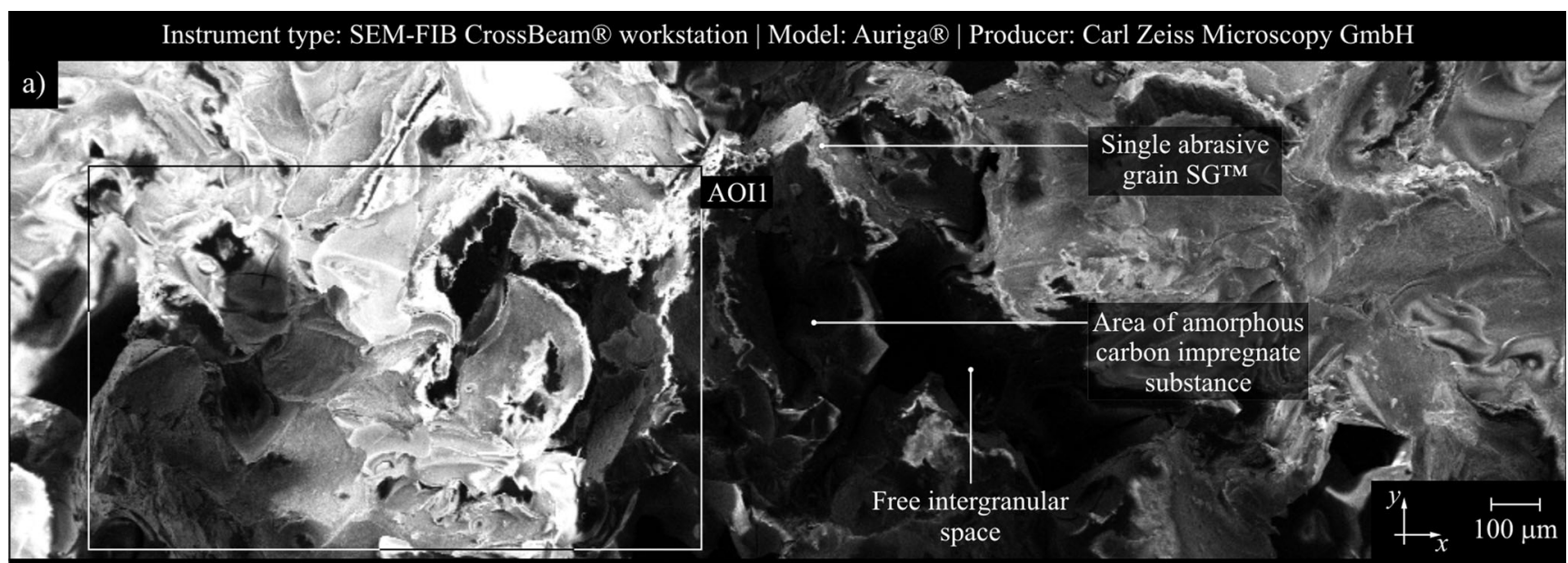

Magnification: $66 \times \mid$ Acc. voltage: $5 \mathrm{kV} \mid$ Image size: $3.20 \times 1.01 \mathrm{~mm}$ | Signal A: SESI | WD: $4.3 \mathrm{~mm}$ | FIB mode: imaging

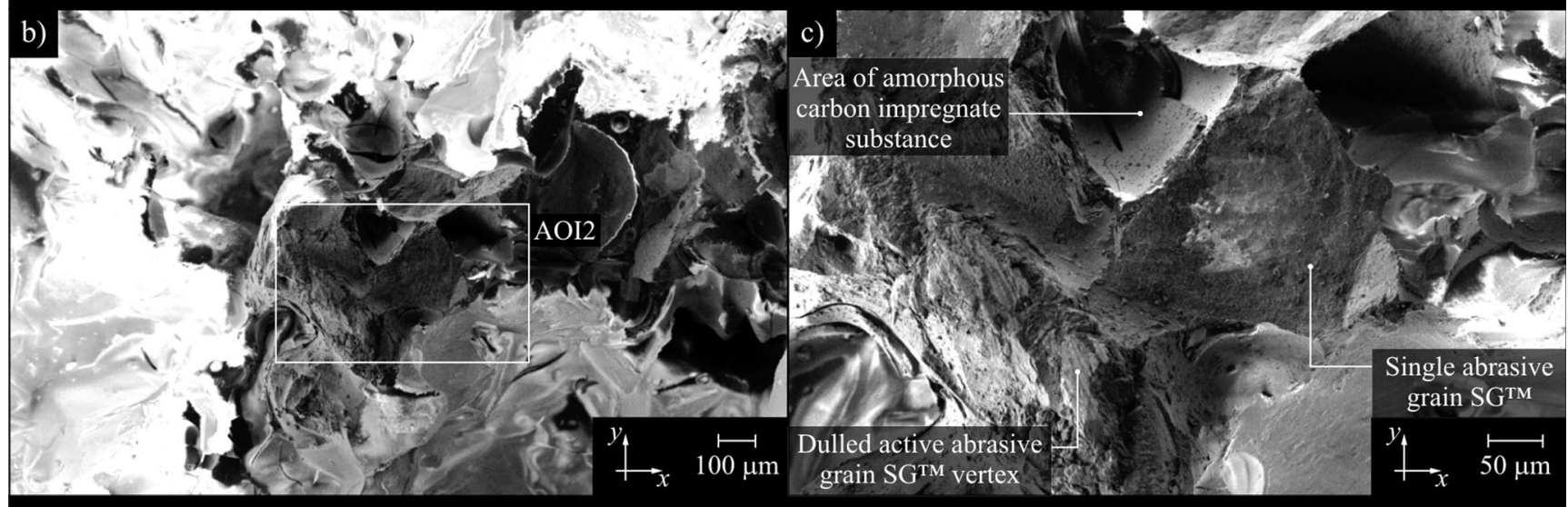

AOI: 1 | Magnification: $100 \times$ | Acc. voltage: $5 \mathrm{kV}$ | Image size: $2.10 \times 1.35 \mathrm{~mm}$ | Signal A: SESI | WD: $4.1 \mathrm{~mm}$ | FIB mode: imaging |

Fig. 9 Collection of selected results obtained for the amorphous carbon impregnated GWAS $1-35 \times 10 \times 10$-SG/F46G10VTO after the reciprocal internal cylindrical grinding of Titanium Grade $2^{\circledR}$ alloy (sample 2) by the use of Auriga ${ }^{\circledR}$ SEM-FIB CrossBeam ${ }^{\circledR}$ produced by Carl Zeiss Microscopy GmbH: a SEM micrograph (size $=3.20 \times 1.01 \mathrm{~mm}$, mag.
AOI: 2 | Magnification: $296 \times$ | Acc. voltage: $5 \mathrm{kV}$ | Image size:

$0.71 \times 0.45 \mathrm{~mm}$ | Signal A: SESI | WD: $4.1 \mathrm{~mm}$ | FIB mode: imaging |

$66 \times)$ of a vast panorama of examined GWAS with marked AOI; b SEM micrograph $($ size $=2.10 \times 1.35 \mathrm{~mm}$, mag. $100 \times)$ of AOI 1 extracted from Fig. 9b. c SEM micrograph $($ size $=0.71 \times 0.45 \mathrm{~mm}$, mag. $296 \times)$ of AOI 2 extracted from Fig. 9b 


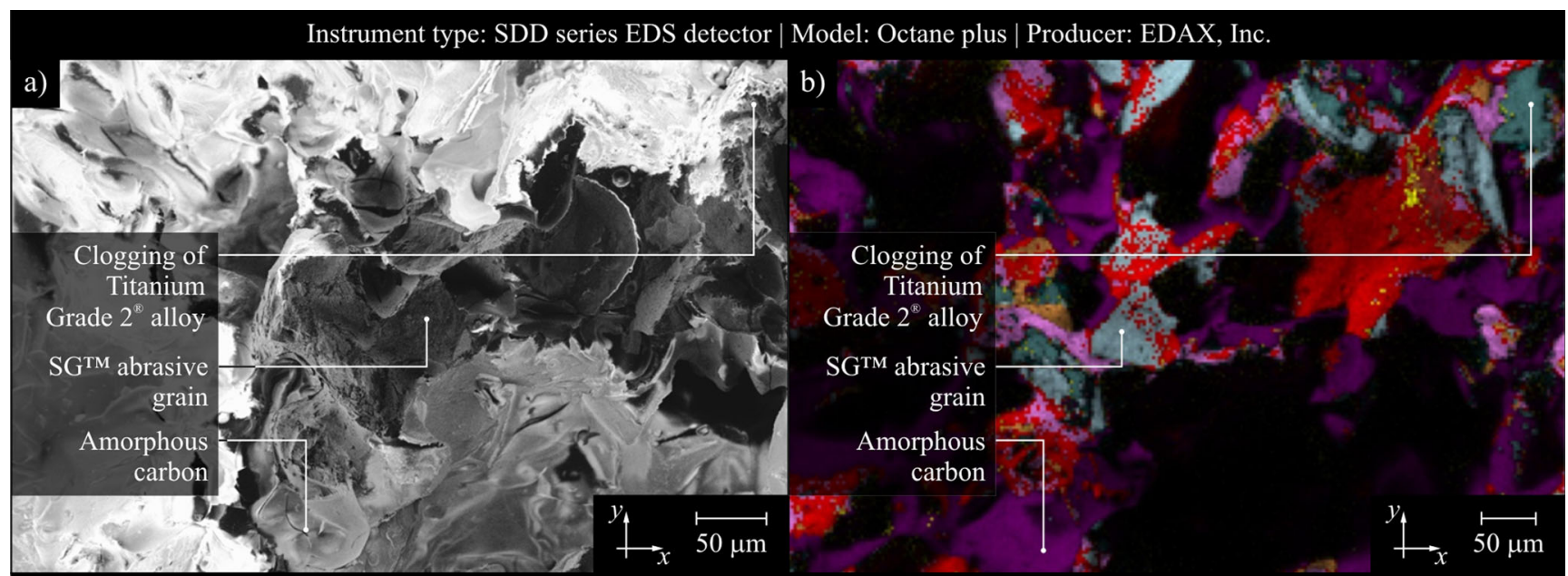

AOI: 2 | Magnification: $100 \times$ | Acc. voltage: $5 \mathrm{kV}$ | Image size:

AOI: 2 | Analysis: microanalysis EDS - elements map

$2.22 \times 1.47 \mathrm{~mm}$ | Signal A: SESI | WD: $4.1 \mathrm{~mm} \mid$ FIB mode: imaging Software: TEAM ${ }^{\mathrm{TM}} \mid$ Producer: EDAX, Inc.

c)

C: $38 \%$

$\mathrm{Mg}: 2 \%$
O: $24 \%$

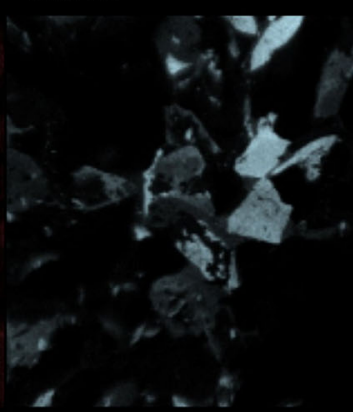

Al: $14 \%$

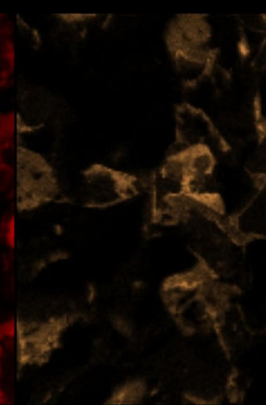

Na: $4 \%$

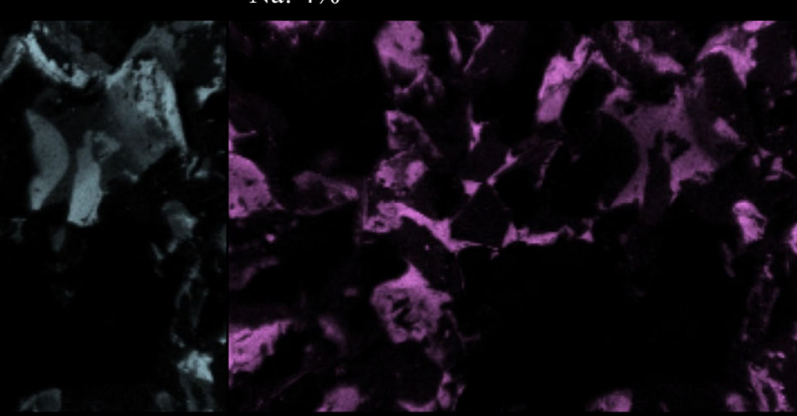

Si: $8 \%$
Fig. 10 Collection of selected results obtained for the amorphous carbon impregnated GWAS 1-35 × $10 \times 10$-SG/F46G10VTO after the reciprocal internal cylindrical grinding of Titanium Grade $2^{\circledR}$ alloy (Sample 2) by the use of Auriga ${ }^{\circledR}$ SEM-FIB CrossBeam ${ }^{\circledR}$ workstation produced by Carl
Zeiss Microscopy GmbH and Octane plus EDS detector produced by EDAX, Inc.: a SEM micrograph $($ size $=2.22 \times 1.47 \mathrm{~mm}$, mag. $100 \times)$ of AOI; b microanalysis EDS - elements map of the AOI 2; c elements and their percentage of the analyzed AOI 2 
composition of AOI 2 presented in Fig. 8. Other elements shown in both the EDS analysis for AOI 1 and AOI 2 represented a material of the abrasive grain composed of microcrystalline $\mathrm{Al}_{2} \mathrm{O}_{3}$, as well as compounds contained in the vitrified glass-crystalline structure. The bond used for the construction of the grinding wheels is one of the ceramic materials of the CMAS (CaO-MgO- $\left.\mathrm{Al}_{2} \mathrm{O}_{3}-\mathrm{SiO}_{2}\right)$ [37]. It should be emphasized that the final result of the analysis was affected by the pollution which result from the grinding process, e.g., grinding fluids $[34,35]$.

For imaging and analysis of other fragment of the GWAS, marked as a sample 2, Auriga ${ }^{\circledR}$ SEM-FIB CrossBeam ${ }^{\circledR}$ produced by Carl Zeiss Microscopy GmbH was also used. The output SEM micrograph $($ size $=3.20 \times 1.01 \mathrm{~mm}$, mag. $66 \times$ ) shows a vast panorama of examined GWAS without any clogging areas (Fig. 9a), which were observed for sample 1-AOI 1 and AOI 2 (Fig. 3b, 6b). This GWAS was generally devoid of visible pollution, allowing to present its characteristic elements, such as: a single abrasive grains $\mathrm{SG}^{\mathrm{TM}}$, areas of concentrate of the amorphous carbon impregnate substance, and randomly located free intergranular spaces. From SEM micrograph (Fig. 9a), an AOI 1 (size $=2.10 \times 1.35 \mathrm{~mm}$, mag. $100 \times$ ) was extracted with interesting area including a single abrasive $\mathrm{SG}^{\mathrm{TM}}$ covered by impregnating substance (Fig. 9b). The AOI 1 was magnified and presented as an AOI 2 $($ size $=0.71 \times 0.45 \mathrm{~mm}$, mag. $296 \times)$ in Fig. 9c. For this AOI, the microanalysis EDS (Fig. 10b) was carried out. In this case, the same procedures were used such as in previous analysis carried out for Sample 1/AOI 1 and Sample 1/AOI 2.

In this AOI, a large concentration of carbon ( $38 \%$ ), oxygen ( $24 \%)$, as well as aluminum (14\%) was observed. The concentration of the rest of elements was smaller and occurred in a range from 8 to $2 \%$. A percentage of the carbon, highlighted by violet (Fig. 10c), was from 7 to $17 \%$ higher in relation to sample 1/AOI 1 and sample 1/AOI 2, respectively. The impregnating substance in this AOI was properly introduced, which was characterized by its even distribution. As previously mentioned, AOI 1 was free from areas clogged by Titanium Grade $2^{\circledR}$. The percentage of this alloy, highlighted by azure
(Fig. 10c) was relatively small (6\%), in relation to carried out earlier analysis. From CMAS, the highest value was obtained for aluminum (14\%), for silicon ( $8 \%$ ), as well as for calcium and magnesium (2\%). The analysis from Fig. 10 closely correspond with EDS spectrum containing also an elemental composition of AOI 1 presented in Fig. 11.

During the grinding process of titanium, which is a very reactive material, using an abrasive wheel, the thin passive layer of titanium oxides/hydroxides is created. In addition, it has to be pointed that for that abrasive treatment, a high temperature is accompanied. Therefore the coolant Castrol Syntilo RHS, which contains organic compounds such as: diethanolamine; 2,2'-iminodiethanol, acid ethoxylates, carboxylic acids with amines, 2,2'-iminobis(ethanol), and 2-(2-butoxyethoxy)ethanol, was also used. In environment containing a lot of organic carbon-hydrogen compounds with accompanying of high temperature, the titanium parts can form chemical compounds with carbon as well as with hydrogen, which unfortunately cannot be detected by the EDS method.

\section{Conclusions}

Conducted SEM-EDS analysis allowed for the unambiguous identification of the distribution of chemical elements on the analyzed three areas of amorphous carbon-treated grinding wheel active surface after reciprocal internal cylindrical grinding of Titanium Grade $2^{\circledR}$ alloy. This enabled the determination of the percentage and the shape and arrangement of cloggings which resulted from Ti chips adhesion to the GWAS. In this study, it was also very important to determine the share of impregnating substance (amorphous carbon) on the GWAS after the grinding process.

The most important conclusions that can be drawn from the research carried out include the following:

- Applied impregnation method ensure in an effective way the presence of impregnate in a grinding wheel body, also in subsequent work cycles of tool;
Fig. 11 EDS spectrum with an elements contained in the analyzed amorphous carbon impregnated GWAS $1-35 \times 10 \times 10-$ SG/F46G10VTO after the reciprocal internal cylindrical grinding of Titanium Grade $2^{\circledR}$ alloy by the use of Octane plus EDS detector produced by EDAX, Inc. for Sample 2, AOI 2

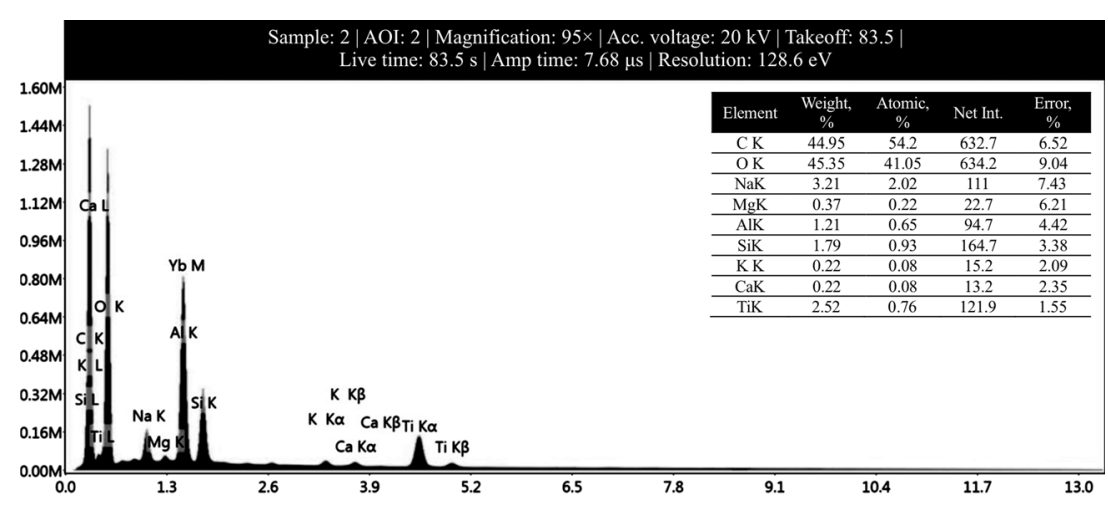


- Analysis shows that share of carbon on the GWAS is relatively high: in the range of $21-38 \%$;

- Participation of Ti on the GWAS was from 6 up to $13 \%$ for the area with vast clogging (sample 1, AOI 2);

- Observed Ti cloggings on the GWAS appear solely on dulled vertices of active abrasive grains, which demonstrates the limited impact of the impregnate in the zone of direct contact between abrasive grains and machined workpiece surface;

- Lack of extensive cloggings of the intergranular spaces indicating an effective removal of long ductile chips of $\mathrm{Ti}$ from grinding zone - it can be assumed that this phenomena is aided by the introduction of an anti-adhesive impregnating substance;

- Elements identified on the GWAS with the use of SEMEDS technique correspond to the knowledge about the chemical structure of the components of evaluated grinding wheel.

The authors in the next works are planning to conduct analyzes of the active surfaces of grinding wheels impregnated with other impregnating substances (including graphite, silicone, molybdenum disulfide $\mathrm{MoS}_{2}$, and hexagonal boron nitride $\mathrm{hBN}$ ) after grinding process of hard-to-cut materials.

Acknowledgments The authors would like to thank the employees of Koszalin University of Technology for their help and support in selected steps of the experimental studies: Prof. Daniela Herman, DSc, PhD, from the Division of Fundamentals of Materials Science and Technical Ceramics of the Faculty of Technology and Education, for preparing the grinding wheels for tests; Prof. Walery Sienicki, DSc, $\mathrm{PhD}$ and Michał Wojtewicz, MSc, BSc from the Subject Group of Applied Chemistry of the Faculty of Mechanical Engineering for impregnation of the grinding wheels; Mr. Ryszard Gritzman from the Laboratory of Electron Microscopy and the Structural Research, Central Laboratory of the Faculty of Technology and Education for acquisition of the SEM micrographs of analyzed grinding wheels, as well as Mr. Andrzej Nowicki from Laboratory Team I of the Faculty of Mechanical Engineering for his help during experimental studies of the grinding process.

\section{Compliance with ethical standards}

Funding This study did not receive any grant funding.

Conflict of interest The authors declare that they have no conflict of interest.

Open Access This article is distributed under the terms of the Creative Commons Attribution 4.0 International License (http:// creativecommons.org/licenses/by/4.0/), which permits unrestricted use, distribution, and reproduction in any medium, provided you give appropriate credit to the original author(s) and the source, provide a link to the Creative Commons license, and indicate if changes were made.

\section{References}

1. Leyens C, Peters M (2006) Titanium and titanium alloys: fundamentals and applications. John Wiley \& Sons, Weinheim

2. Yang X, Liu CR (1999) Machining titanium and its alloys. Mach Sci Technol 3(1):107-139

3. Neslušan M, Czán A (2001) Machining of titanium and nickel alloys. EDIS, Žilina in Slovak

4. Xu X, Yu Y, Huang H (2003) Mechanisms of abrasive wear in the grinding of titanium (TC4) and nickel (K417) alloys. Wear 256(712):1421-1426

5. Teicher U, Ghosh A, Chattopadhyay AB, Künanz K (2006) On the grindability of titanium alloy by brazed type monolayered superabrasive grinding wheels. Int J Mach Tool Manu 46(6):620 622

6. Hood R, Lechner F, Aspinwall DK, Voice W (2007) Creep feed grinding of gamma titanium aluminide and burn resistant titanium alloys using SiC abrasive. Int J Mach Tool Manu 47:1486-1492

7. Ulutan D, Ozel T (2011) Machining induced surface integrity in titanium and nickel alloys: a review. Int J Mach Tools Manuf 51(3): 250-280

8. Ding WF, Xu JH, Chen ZZ, Su HH, Fu YC (2011) Grain wear of brazed polycrystalline $\mathrm{CBN}$ abrasive tools during constant-force grinding Ti-6Al-4Valloy. Int J Adv Manuf Technol 52(9):969-976

9. Dai C, Ding WF, Xu J, Xu JX, Fu D (2016) Effects of undeformed chip thickness on grinding temperature and burn-out in highefficiency deep grinding of Inconel718 superalloys. Int J Adv Manuf Technol. doi:10.1007/s00170-016-9192-1

10. Kremen ZI (2003) A new generation of high-porous vitrified cBN wheels. Ind Diam Rev 63(4):53-56

11. Davis TD, DiCorleto J, Sheldon D, Vecchiarelli J, Erkey CA (2004) Route to highly porous grinding wheels by selective extraction of pore inducers with dense carbon dioxide. J Supercrit Fluids 30(3): 349-358

12. Neslušan $M$ (2009) Grinding of Ni-based alloys with grinding wheels of high porosity. Advances in Production Engineering \& Management 4(1-2):29-36

13. Orlhac X, Jeevanantham M, Krause R, Wu M (2010) Abrasive tools having a permeable structure. Patent 7722691 , USA

14. Webster J, Tricard M (2004) Innovations in abrasive products for precision grinding. CIRP Ann - Manuf Techn 53(2):597-617

15. Chirkov GV (2007) Characteristics of the grinding wheel impregnation processes. Russ Eng Res 27(6):387-389

16. Harmann ML (1927) Abrasive article. Patent 1615271, USA

17. Jones HH (1941) Composition for impregnating grinding wheels. Patent 2240302, USA

18. Jackson LP (1943) Filled abrasive article and filler for the same. Patent 2333480, USA

19. Gallagher TP (1967) Process for impregnating porous bodies with a solid fusible substance. Patent 3341355, USA

20. Kitajima M, Unno K, Takehara H, Kono T, Soma S (2010) Segmented grinding wheel and manufacturing method therefor. Patent 2010/0261420A1, USA

21. Wu M, Carman LA, Aspensjo L (2000) High speed grinding wheel. Patent 6047278, USA

22. Tsai MY, Jian SX (2012) Development of a micro-graphite impregnated grinding wheel. Int J Mach Tool Manu 56:94-101

23. Nadolny K, Kapłonek W, Wojtewicz M, Sienicki W (2013) The assessment of sulfurization influence on cutting ability of the grinding wheels in internal cylindrical grinding of titanium grade $2^{\circledR}$. Indian J Eng Mater S 20(2):108-124

24. Kapłonek W, Nadolny K, Wojtewicz M, Sienicki W (2015) Characterisation of abrasive tools active surface after the impregnation process by modified ARS method based on imaging and 
analysis of the scattered light. Int J Machining and Machinability of Materials 17(5):397-417

25. Luo SY, Liao YS, Chou CC, Chen JP (1997) Analysis of the wear of a resin-bonded diamond wheel in the grinding of tungsten carbide. J Mater Process Tech 69(1-3):289-296

26. Shaji S, Radhakrishnan V (2002) An investigation on surface grinding using graphite as lubricant. Int J Mach Tool Manu 42(6):733740

27. Shaji S, Radhakrishnan V (2003a) Analysis of process parameters in surface grinding with graphite as lubricant based on the Taguchi method. J Mater Process Tech 141(1):51-59

28. Shaji S, Radhakrishnan V (2003b) Application of solid lubricants in grinding: investigations on graphite sandwiched grinding wheels. Mach Sci Technol 7(1):137-155

29. Salmon SC (2003) The effects of hard lubricant coatings on the performance of electro-plated superabrasive grinding wheels. Key Eng Mat 238-239:283-288

30. Irani RA, Bauer RJ, Warkentin A (2005) A review of cutting fluid application in the grinding process. Int J Mach Tool Manu 45(15): 1696-1705

31. Alberts M, Kalaitzidou K, Melkote S (2009) An investigation of graphite nanoplatelets as lubricant in grinding. Int J Mach Tool Manu 49(12-13):966-970
32. Pierson HO (1993) Handbook of carbon, graphite, diamonds and fullerenes: processing, properties and applications. Noyes Publications, Park Ridge

33. Nadolny K, Sienicki W, Wojtewicz M (2015) The effect upon the grinding wheel active surface condition when impregnating with non-metallic elements during internal cylindrical grinding of titanium. Arch Civ Mech Eng 15(1):71-86

34. Herman D (1998) Glass and glass-ceramic binder obtained from waste material for binding alundum abrasive grains into grinding wheels. Ceram Int 24(7):515-520

35. Herman D, Markul J (2004) Influence of microstructures of binder and abrasive grain on selected operational properties of ceramic grinding wheels made of alumina. Int J Mach Tool Manu 44(5): 511-522

36. Sienicki W, Wojtewicz M, Nadolny K (2011) Method of modifying ceramic abrasive tools by impregnation. Polish patent application No. P. 395441 from 27.06.2011

37. Mercer C, Faulhaber S, Evans AG, Darolia R (2005) A delamination mechanism for thermal barrier coatings subject to calciummagnesium-alumino-silicate (CMAS) infiltration. Acta Mater 53(4):1029-1039 